\title{
A MEDULLOBLASTOMA IN AN INFANT WITH ABNORMAL CELLS IN THE CEREBROSPINAL FLUID
}

\author{
BY \\ F. WALT, M.R.C.S., L.R.C.P., D.C.H. \\ (From the Paddington Green Children's Hospital)
}

This case of an intracranial tumour in an infant is thought to be worthy of record because, in spite of symptoms suggesting meningitis, a correct diagnosis was made possible by the unusual characters of the cerebrospinal fluid.

\section{Clinical Record}

C. H., a male child aged one year and nine months was brought to hospital with a left-sided facial paralysis which had developed suddenly five days previously. He seemed quite well in himself and did not appear to be in any pain. On examination it was found that the drum of the left ear was of pink colour and showed an attic bulge. The drum was incised, but pus was not obtained. The right ear was normal. He appeared to remain quite well until thirteen days later, when he became restless and irritable with a low, whining cry. Both ears at this time looked normal and he was admitted to the ward for observation.

General examination revealed a miserable infant. He was restless, waved his arms about continually, threw his head backward and forward and took no interest in his surroundings.

Physical examination elicited a positive Kernig's sign and some definite head retraction. The facial palsy was infranuclear in type. There were no apparent lesions of the other cranial nerves and all reflexes were obtained. There was a leucocytosis of 17,500 cells per c.mm., but there was no pronounced increase in the number of polymorphonuclear cells. The Wassermann reaction in the blood was negative.

Three specimens of cerebrospinal fluid were obtained by lumbar puncture at intervals of four days. The fluid was never under marked pressure. These three specimens were similar in character. The fluids were slightly turbid and deposited a small amount of bright blood. A small soft grey clot developed in the fluids after a short interval. The number of cells in the fluids averaged 430 per c.mm. These cells were quite unlike those associated with meningeal inflammation. Many of them were considerably larger and most of them were more refractile. The characters of the cells were best observed in the counting chamber, for many were disintegrated by the centrifuge in the preparation of films. The predominant cell was large and round, with a well-defined eccentric nucleus and clear protoplasm. Other cells with an obscured nucleus were filled with dark granules, whilst others had lost their outlines and were markedly degenerate. Occasionally these cells were met with in small clumps, but no clump contained more than six cells. These abnormal cells constituted more 
than 90 per cent. of the whole number. Such other cells as were present were polymorphonuclear cells and lymphocytes that probably came from the blood in the fluids. The fluid protein was much increased, the chloride content was normal. Tubercle bacilli and other organisms were not identified in films and cultures proved sterile.

Twenty-one days after the onset of the facial paralysis the temperature, which had been normal, rose to $103^{\circ} \mathrm{F}$. and continued high for four days. Nothing, at first, could be found to account for this temperature, but he later developed an otitis media in the right ear. After myringotomy the temperature gradually returned to the normal. At this stage he developed a left-sided hemiplegia. Neither the left arm nor the left leg was moving, the cremasteric reflex was present on the right side, but not on the left, and a positive Kernig's sign present on the right side was unobtainable on the left side. This hemiplegia proved to be transient and disappeared within five days leaving no residual paralysis.

The child became worse, was still irritable and had photophobia and marked head retraction. At no time, however, did vomiting become a symptom and no papilloedema was ever detected. The child became comatose and died exactly five weeks after the onset of his disease.

At the post-mortem examination a soft and heavy brain was found and over the base of the brain there was an extensive tumour growth. It was a dirtygrey colour, soft and friable. It extended from the cerebellum posteriorly to the frontal lobes in front. The largest mass of growth was found in the pons and cerebral peduncles. It entirely obliterated their structure and by extension upwards had forced up the floor of the third ventricle, reducing its cavity to a mere slit. The growth extensively infiltrated the more superficial portions of the cerebellum and was present in the posterior part of the fourth ventricle as a soft, cauliflower-like mass. On the under-surface of the cerebellum the tumour growth looked like a superficial grey plaque. Anteriorly it entirely obliterated the optic chiasma and passed forward along the optic nerves and the olfactory tracts. In the frontal lobes adjacent to the olfactory tracts were found two discrete tumour nodules, one in each cerebral hemisphere. The lateral ventricles were dilated and contained a great excess of fluid. This dilatation was thought to be due to the partial closure of the third ventricle, for the fourth ventricle was not markedly dilated. The growth invaded the sub-arachnoid spaces and was present along the cranial nerves in their intracranial course as a soft, grey and ragged sheath. A small amount of pus was found in the right middle ear : the left ear was clean. Histologically the growth was found to be a typical medulloblastoma.

\section{Comment}

The clinical features of this case were puzzling until the correct diagnosis of the child's condition was established by the examination of the cerebrospinal fluid. The objective signs of meningitis-head retraction, Kernig's sign, restlessness and facial paralysis-were complicated by an irregular pyrexia due to a concurrent otitis media. The clinical picture was that of meningitis, but the cells of the cerebrospinal fluid were wholly different from those associated with inflammatory disease. They could at once be recognized in the counting chamber as quite abnormal by their large size, granularity and other histological characters.

Abnormal cells like these have previously been described in the fluid in cases of medulloblastoma, but they are distinctly uncommon. Ford (1937) mentions 
the case of an infant with symptoms very similar to those now described in which tumour cells were found in the fluid, while Merritt and Fremont-Smith (1937) write of their occurrence in the cerebrospinal fluid as a matter of 'great rarity.' These observers, however, seem to note such cells as affording confirmatory evidence of the presence of a tumour already diagnosed as such on clinical grounds. In the present case these abnormal cells were the only significant factors in the satisfactory solution of an interesting clinical problem. The appearances of the brain at autopsy account, in some measure, for the resemblance of the clinical picture to that of meningitis. In a fatal case of acute basal meningitis in infancy the base of the brain from the medulla forward is found clothed with pus and there is often an associated dilatation of the ventricles. In this child's brain there was no pus, but there was, instead, a rapidly growing soft tumour mass of almost identical distribution with considerable dilatation of the lateral ventricles. The sub-arachnoid spaces were filled with growth and the meningeal irritation was of neoplastic origin. This child was too young to complain of headache, but it is of interest that other signs of intracranial tumour, such as vomiting and papilloedema, were never, at any time, a feature of the disease. Ford notes the absence of papilloedema in about one quarter of the cases of medulloblastoma in infancy that have so far been described.

Thanks are due to Dr. Reginald Miller for permission to record this case.

\section{REFERENCES}

1. Ford, F. R. (1937). Diseases of the Nervous System in Infancy, Childhood and Adolescence, London, 679.

2. Merritt, H. and Fremont-Smith, F. (1937). The Cerebrospinal Fluid, London, 162. 